\title{
Light intensity is a limiting factor to the inland expansion of Cape ivy (Delairea odorata)
}

\author{
Ramona A. Robison • Guy B. Kyser • \\ Kevin J. Rice $\cdot$ Joseph M. DiTomaso
}

Received: 26 October 2009/Accepted: 17 May 2010/Published online: 29 May 2010

(C) The Author(s) 2010. This article is published with open access at Springerlink.com

\begin{abstract}
Cape ivy (Delairea odorata) is a highly invasive climbing perennial vine that is primarily distributed in coastal communities of California and Oregon, with patchy infestations in some inland riparian areas. In this study, we evaluated light as a potential environmental limitation to the spread of Cape ivy into inland regions of the western United States. Cape ivy was collected from four locations representing the north to south range. Plants were grown for 9 to 11 weeks in full sunlight and under two shade regimes (20 and $6 \%$ of full sunlight). The experiment was conducted twice at two temperature regimes. Results show some within- and among-population variability, with the southernmost San Diego County population having the highest biomass under the warmer growing conditions and the three northern populations responding most favorably in the cooler growing conditions. Despite the minor differences within and between populations, Cape ivy grew very poorly in full sunlight in both experiments. Although plants growing under $6 \%$ light grew better than those in full sunlight, they were far less robust compared to plants growing at 20\% light. Our results indicate that while Cape ivy will not persist in areas with prolonged high intensity sunlight,
\end{abstract}

R. A. Robison

ICF International, Sacramento, CA, USA

G. B. Kyser · K. J. Rice · J. M. DiTomaso ( $\square)$ Department of Plant Sciences, University of California, Mail Stop 4, One Shields Ave., Davis, CA 95616, USA

e-mail: jmditomaso@ucdavis.edu characterized by much of the interior regions of California and Oregon, it is expected to invade and spread in areas with reduced light, including coastal regions frequently exposed to fog or cloudy conditions, or sub-canopy layers of riparian forests or woodlands. These communities should be the target areas for early detection and rapid response programs to prevent further Cape ivy invasion.

Keywords Riparian · Invasive plant . Genetic variability $\cdot$ Light suppression

\section{Introduction}

Cape ivy (Delairea odorata Lem.; syn. Senecio mikanioides Walpers) was introduced to the eastern United States as an ornamental houseplant in the 1850s. It was first collected in the wild in Berkeley in 1892 (Robison 2006) by the 1960s had escaped to become invasive in the San Francisco Bay Area (Bossard 2000). Cape ivy has also escaped cultivation to invade wildlands in Europe, Australia, New Zealand, Hawaii, and South America (Bossard 2000; Robison et al. 2010). In California, it generally invades coastal forest sites, and appears to prefer shady, disturbed areas with year-round moisture, such as stream banks and forests within the coastal fog belt where it often climbs over other vegetation and 
reduces native plant diversity (Alvarez and Cushman 2002). More recently, populations have expanded into grasslands, open oak forests, scrublands, Monterey pine forests, bluff communities, seasonal wetlands, and even a few serpentine soils (Bossard 2000). However, all these invaded habitats are restricted to locations within a few kilometers of the coast.

In its native range in South Africa, Cape ivy has a limited distribution, but is found in diverse habitat types ranging from near desert to high mountain Podocarpus forest edges (Hilliard 1977; Grobbelaar et al. 1999; Rolando 2000). Despite the wide range of habitats, it is reported to primarily grow in moist, shady environments along forest edges (Robison et al. 2010; Rolando 2000).

Cape ivy is an obligate outcrossing species that reproduces sexually in its native range (Rolando 2000). In its invaded range, viable seeds are produced only when populations introgress and outcrossing is possible. Until 2001 there was no report of viable seed in escaped populations in California (Bossard 2000). Since then, some populations have been shown to produce viable seed, though most are still considered sterile (Robison 2006). Although little is known of the genetic or phenotypic diversity present within or among California Cape ivy populations, we hypothesize that most invasive populations are clonal expansions.

While it is possible that low reproductive output in most populations is a limiting factor in the spread of Cape ivy in California and Oregon, Robison (2006) used a climate matching model (CLIMEX) to show that Cape ivy has nearly fully occupied its predicted range (Robison et al. 2010), which appears to be nearly restricted to coastal habitats. Thus, we further hypothesize that the factor restricting inland expansion of Cape ivy is an intolerance of high light intensity typical of most Mediterranean climatic regions of California and Oregon. The objective of this study was to evaluate the growth response of Cape ivy to varying light intensity in four clonal populations within a north to south cline ranging from southern Oregon to southern California.

\section{Materials and methods}

Clonal populations and propagation

Stem cuttings were collected from February to March, 2003, from four populations representing a north to south clinal range (Table 1). There are two known morphological forms (stipulate and exstipulate) of Cape ivy in its native range of South Africa and its invasive range along the west coast of the United States (Robison 2006) and both of these morphological types were represented in this study. One population was from Curry County, Oregon, while the other three were from coastal areas in California, including Mendocino, Marin, and San Diego counties. Of these, two populations were growing in open habitats (Curry and Mendocino counties) and two were under a forest canopy (Marin and San Diego counties). The northernmost collection was from Curry County, Oregon, in the coastal town of Pistol River. The location was in full sun and the plants were of the exstipulate morphological type. The second population, from Mendocino County at Schooner Gulch, was stipulate and grew in full sun in a coastal environment. It was in a mixed community with a dense growth of big periwinkle (Vinca major L.) and poison-hemlock (Conium maculatum L.). The third population, from Marin County, along Highway 1 north of Bolinas, was comprised of plants that were stipulate and growing in the shade of willows (Salix spp.). The southernmost population collected was from Marian Bear State Park in San Diego County. These plants were exstipulate and grew in the shade of coast live oak (Quercus agrifolia Née).

At each population, five stem pieces with four or more nodes were collected from locations at least five meters apart. To minimize site-specific maternal environmental effects, each collection was vegetatively propagated and grown in the same greenhouse at the University of California, Davis.

Two-node sections from each of the five daughter plants, referred to as 'genotypes,' collected from the four populations were cut and planted in greenhouse soil (modified UC $\operatorname{mix}^{1}$ ), with one node below and one above the soil surface. These stock plants were placed on a mist bench with bottom heating until roots had established. Stock plants were then moved to another greenhouse until initiation of the experiment.

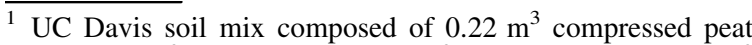
moss, $0.23 \mathrm{~m}^{3}$ sponge rock, $0.11 \mathrm{~m}^{3} \# 2$ vermiculite, $0.17 \mathrm{~m}^{3}$ sand, $2.27 \mathrm{~kg}$ dolomite, $0.7 \mathrm{~kg}$ 14-14-14 fertilizer, $0.7 \mathrm{~kg}$ Micromax ${ }^{\mathrm{TM}}$ micronutrient fertilizer. Sierra Chemical Co., 1001 Yosemite Dr., Milpitas, CA 95035.
} 
Table 1 Collection locations, morphological type, growth conditions, reproductive ability, precipitation, and maximum/minimum temperature ranges for Cape ivy populations used in the two experiments

\begin{tabular}{|c|c|c|c|c|c|c|}
\hline $\begin{array}{l}\text { County } \\
\text { location }\end{array}$ & $\begin{array}{l}\text { Morphology } \\
\text { type }\end{array}$ & $\begin{array}{l}\text { Population } \\
\text { growth conditions }\end{array}$ & $\begin{array}{l}\text { Viable } \\
\text { seeds }\end{array}$ & $\begin{array}{l}\text { Mean annual } \\
\text { precipitation }(\mathrm{mm})\end{array}$ & $\begin{array}{l}\text { Mean annual max } / \min \\
\text { temperature range }\left({ }^{\circ} \mathrm{C}\right)\end{array}$ & Latitude \\
\hline Curry (OR) & Exstipulate & Full sunlight & Yes & 2,020 & $20.3 / 4.8$ & 42.28 \\
\hline Mendocino & Stipulate & Full sunlight & No & 1,279 & $20.3 / 3.9$ & 38.87 \\
\hline Marin & Stipulate & Shade & Yes & 1,026 & $21.8 / 5.0$ & 37.94 \\
\hline San Diego & Exstipulate & Shade & No & 322 & $25.9 / 7.5$ & 32.83 \\
\hline
\end{tabular}

Cape ivy establishment and treatments

The experiment was repeated twice in 2003, once beginning on April 26 and a second time on September 4. The same stock plants were used for both experiments. Three-two-node clonal sections were propagated from each of the 20 stock genotypes (representing four populations). Each two-node starting segment was weighed and the length recorded. The mean weight of the two-node cuttings was $0.7 \mathrm{~g}$ $( \pm 0.2 \mathrm{~g} \mathrm{SD})$ and the mean length was $15.6 \mathrm{~mm}$ $( \pm 3.2 \mathrm{~mm} \mathrm{SD})$ in April, and $0.3 \mathrm{~g}( \pm 0.2 \mathrm{~g} \mathrm{SD})$ and $11.0 \mathrm{~mm}( \pm 4.2 \mathrm{~mm} \mathrm{SD})$, respectively, in September. The cuttings were planted in 3.81 pots filled with greenhouse potting mix. Plants were grown in a lath house for 2 weeks before exposure to full sunlight or shade treatments. During the experiment, plants were watered to saturation 4 days a week with an automatic watering system that also delivered nutrients (GrowMore 10-15-20 No Boron). The temperatures in Davis ranged between 41.7 and $7.2^{\circ} \mathrm{C}$ during the first experiment and between 40 and $0.6^{\circ} \mathrm{C}$ in the second experiment. The mean maximum and minimum temperatures were 32.4 and $12.8^{\circ} \mathrm{C}$, respectively, in the first experiment, and 26.0 and $8.7^{\circ} \mathrm{C}$ in the second experiment.

To determine the appropriate shade treatments, light levels were measured with a Decagon Sunfleck Ceptometer $^{2}$ within Cape ivy populations in Marin County on March 27, 2003. The light levels were between 4 and $22 \%$ of full sunlight. Thus, experimental light treatments were established at full sunlight, and 6 and $20 \%$ of full sunlight using shade cloth. The shading treatments were achieved with a single layer of shade cloth in the $20 \%$ sunlight

\footnotetext{
${ }^{2}$ Decagon Sunfleck Ceptometer, model SF-80. Manufactured by Decagon Devices, Inc., Pullman, Washington, 99163. http://www.decagon.com.
}

treatment and a double layer in the $6 \%$ sunlight treatment. The experiment consisted of three replicates per treatment arranged in a completely randomized block design. Each replicate contained a clone of the five genotypes from the four populations, for a total of 20 plants per treatment replicate.

The shade structures were built on top of two outdoor wooden benches $0.9 \mathrm{~m}$ wide and $8.4 \mathrm{~m}$ long. The study included two additional benches without shade structures. The shade enclosures were $2.1 \mathrm{~m}$ long by $0.9 \mathrm{~m}$ wide by $1.1 \mathrm{~m}$ tall on the northern bench and $1.4 \mathrm{~m}$ tall on the southern bench. The enclosures consisted of wooden frames with the shade cloth stapled on, and flaps built into the southern end of each enclosure for access. The location of each enclosure or full sunlight treatment was randomly chosen, but full sunlight treatments were given enough space between shaded treatments to minimize shading from the enclosures.

Growth parameters

Starting May 12, 2003, leaf numbers per plant and length of the main stem, branches and internodes were recorded. Measurements were repeated every 8 days for the duration of the experiment. Because of the time required to record all final measurements, plants in the first experiment were harvested between 64 and 77 days after initiation of treatment (June 29 to July 12, 2003) and in the second experiment between 67 and 75 days after treatment (November 10 to 18,2003 ). Each replicated block was harvested within a couple of days to minimize the withinreplicate variability. At harvest, the length of the main Cape ivy vine was recorded, as were the lengths of all lateral branches and the number of internodes. The sum length of the main stem and laterals was considered the total stem length. Leaves were also counted at harvest and total leaf area was determined 
with a Li-Cor 3100 Area Meter. ${ }^{3}$ Following all measurements, the leaves, stems, and roots were dried for at least $24 \mathrm{~h}$ at $70^{\circ} \mathrm{C}$ and weighed.

Data analysis

Plant response data (total stem length, number of internodes, number of leaves, final leaf area, and final biomass of leaves, stems and roots) were analyzed as a split-plot design within each sunlight treatment with percentage of sunlight and population as the main plot factors and genotype as the within plot random factor. Relative growth rate (RGR) was obtained by using the slope of the regression line generated by graphing the log of the total length data for all of the measurement intervals (as described in Hunt 1978). Specific leaf area (SLA), considered the dominant factor in explaining variation in RGR (Poorter and Garnier 1999), was calculated by dividing final leaf area by final leaf dry weight (Hunt 1978). Absolute growth was calculated by dividing the change in total biomass over the course of the experiment by the total number of days.

Data were tested for the ANOVA assumptions of homogeneity of variances, independence and normality. Many of the variables tested were non-normal and/or heteroscedastic and could not be transformed to meet the assumptions, so a ranks averaged transformation was performed on the raw data and ANOVA analyses were completed on ranked values (Conover and Iman 1981). In the case of total dry biomass, analyses were performed on log transformed values. The first and second experiments were analyzed separately. Following ANOVA, means were separated by location, genotype, and sunlight treatment using the Student-Newman-Keuls test at $\alpha=0.05$. The analyses were performed with JMP (SAS Institute 2005).

\section{Results}

\section{Survival}

The number of plants surviving in each sunlight level ranged from 87 to $92 \%$ in the first experiment and 67

\footnotetext{
${ }^{3}$ Li-Cor 3100 Area Meter. Manufactured by Li-Cor Biosciences, Lincoln, Nebraska, 68504. http://www.licor.com.
}

to $78 \%$ in the second experiment. Survival was not significantly different between sunlight levels in the two experiments based on Chi-squared analysis, nor were the two experiments found to be significantly different using a heterogeneity Chi-squared analysis.

Within population variation

The biomass responses of Cape ivy among genotypes nested within populations were significant $(\alpha=0.003)$ in the first experiment conducted at the warmer ambient temperature, but not in the second experiment (Table 2). For RGR in the first experiment, there was a strong main genotype effect $(\alpha=0.0003)$ indicating that the expression of within-population variation was consistent across light treatments. There was also a significant genotype effect in leaf area $(\alpha=0.019)$ and number $(\alpha=0.015)$ in the first experiment. In this experiment, genotype variation within populations was lowest in the most northern (Curry County) and most southern (San Diego County) sites (see Robison 2006 for data), which were the two populations characterized by exstipulate plants (Table 1). In contrast to the first experiment, the expression of within-population genotype variation was not significant in any growth parameter in the second experiment (Table 2), which was conducted later in the year when the average minimum and maximum temperatures were lower.

\section{Between-population variation}

Variation among populations was greater than among genotypes within a population, but only in the first experiment. Populations differed in total biomass, RGR, leaf area, leaf number, number of internodes per plant, and the total stem length in the first experiment, but no significant differences occurred in the second experiment (Table 2). In the interaction between shading treatment and populations, there were significant differences only in the first experiment and only in total biomass and RGR (Table 2).

The observed population variation was not dependent on whether plants were initially collected from sun or shade. In the first experiment, the San Diego County population, which was collected in a shaded location, had significantly higher above- and belowground biomass at the $20 \%$ light level compared to the other three counties (Fig. 1a). This correlated to a consistent and generally significantly higher RGR, 
Table 2 ANOVA comparisons between variables for experiments one and two

\begin{tabular}{|c|c|c|c|c|c|c|c|}
\hline Comparison & $\begin{array}{l}\text { Total } \\
\text { biomass }\end{array}$ & RGR & Leaf area & $\begin{array}{l}\text { Leaf } \\
\text { number }\end{array}$ & SLA & $\begin{array}{l}\text { Number of } \\
\text { internodes }\end{array}$ & $\begin{array}{l}\text { Total stem } \\
\text { length }\end{array}$ \\
\hline \multicolumn{8}{|l|}{ First experiment } \\
\hline Genotypes within populations & $0.0030 * *$ & $0.0003 * * *$ & $0.019^{*}$ & $0.015^{*}$ & 0.060 & 0.077 & 0.056 \\
\hline Population & $0.0015^{* *}$ & $0.034 *$ & $0.0005 * * *$ & $0.0014 * *$ & 0.34 & $0.0008 * * *$ & $0.0002 * * *$ \\
\hline Shading & $0.0007 * * *$ & $0.0008 * * *$ & 0.52 & $0.044 *$ & $0.019^{*}$ & $0.048^{*}$ & 0.11 \\
\hline Shading $*$ population & $0.0071 * *$ & $<0.0001 * * *$ & 0.66 & 0.99 & 0.20 & 0.84 & 0.90 \\
\hline \multicolumn{8}{|l|}{ Second experiment } \\
\hline Genotypes within populations & 0.86 & 0.32 & 0.76 & 0.84 & 0.41 & 0.80 & 0.54 \\
\hline Population & 0.56 & 0.55 & 0.50 & 0.90 & 0.55 & 0.50 & 0.45 \\
\hline Shading & $0.0003 * * *$ & $0.0025 * *$ & $0.045^{*}$ & $0.0008 * * *$ & $0.036^{*}$ & $0.0006 * * *$ & $0.0003 * * *$ \\
\hline Shading $*$ population & 0.56 & 0.74 & 0.43 & 0.60 & 0.45 & 0.54 & 0.66 \\
\hline
\end{tabular}

Light percentage values calculated using separate JMP analysis. Leaf area and Specific Leaf Area (SLA) comparisons did not include full sunlight treatments as most leaves were necrotic by the end of the experiment. $N=162$ for first experiment; $N=122$ for second experiment

$* \alpha<0.05 ; * * \alpha<0.01 ; * * * \alpha<0.001$

leaf area, leaf number, number of internodes per plant, and total stem length in the San Diego County population (Table 3). Only specific leaf area was not significantly higher in the San Diego County population.

The higher biomass of the San Diego County population in the first experiment was in direct contrast to the results obtained in the second experiment (Fig. 1b). In the second experiment, conducted from late summer to autumn, both the above- and below-ground biomass of the San Diego County population were less than the other three counties, although only significantly different from Marin County. In both experiments, there were no significant differences among Curry, Mendocino, and Marin counties in either above- or below-ground biomass (Fig. 1). In addition, there were no significant differences among populations for leaf area, leaf number, specific leaf area, number of internodes, and total stem length in the second experiment (Table 4). The only significant difference in populations, other than biomass, was in RGR, which was slightly higher in the Mendocino County population compared to the other three counties.

Despite the population differences at the $20 \%$ light level in both experiments, there were no significant differences among populations in above- and belowground biomass at full sunlight or at $6 \%$ full sunlight (Fig. 1).
Response to light levels

The response to sunlight levels was dramatically different in nearly all growth parameters for all populations in both experiments (Tables 2, 3 and 4). Plants in the $20 \%$ sunlight treatment produced consistently greater biomass than plants grown in full sunlight or $6 \%$ sunlight (Fig. 1), with correspondingly greater RGR, leaf area, leaf number, number of internodes, and total stem length (Tables 3 and 4). Below-ground biomass was considerably less than above-ground biomass in all cases, and again was highest in plants grown at $20 \%$ sunlight.

In the first experiment, plants in the $6 \%$ light treatment had significantly higher biomass (above- and below-ground), RGR, leaf area, number of internodes, and total stem length than full sun plants (Fig. 1a and Table 3). Results were similar in the second experiment, although only RGR, leaf area, and total stem length were significantly different (Table 4). Although total biomass, leaf number, and number of internodes were consistently higher in the $6 \%$ light treatment, compared to full sunlight, this was not statistically significant at $\alpha<0.05$. As was expected, the lowest light treatment gave the highest specific leaf area value in both experiments (Tables 3 and 4).

Interestingly, the growth of plants in full sunlight in the second experiment was consistently greater than those in the first experiment, which we speculate 

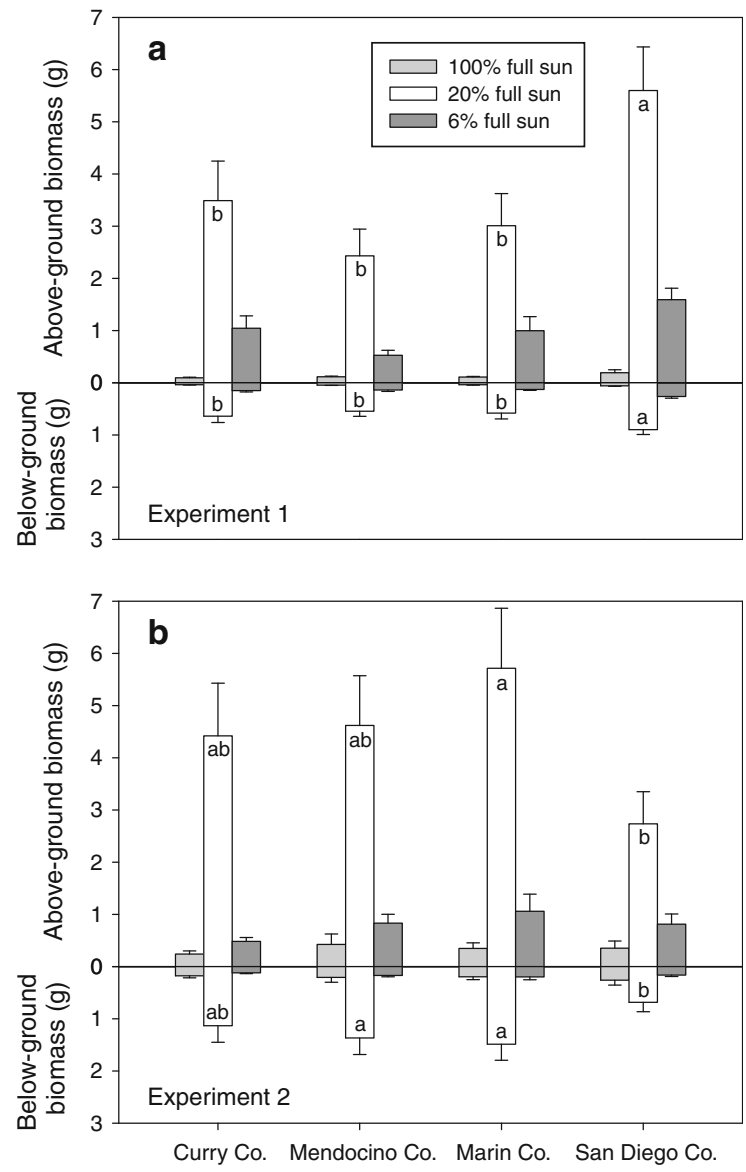

Fig. 1 Comparison of above- and below-ground dry biomass of Cape ivy from four populations at three light treatment levels in a Experiment 1 conducted from April through July and b Experiment 2 conducted from September through November. Bars represent one standard deviation from mean. Bars with different letters indicate significant differences among populations (above- and below-ground biomass) at $\alpha<0.05$

is due to the autumn timing and higher probability for increased number of cloudy days during this time frame.

\section{Discussion}

Variation between and among populations

Although little is known of the genetic diversity of Cape ivy in its native range in South Africa, genotypic variability would be expected to be relatively low due to its limited distribution (Grobbelaar et al. 1999;
Rolando 2000). However, two distinct morphological types have been described, one with and one without rounded stipules (Robison 2006). Because Cape ivy is an obligate outcrosser, we expected to find the lowest genetic variability in the populations that did not produce viable seed (Mendocino and San Diego counties). However, the sites with the least genotypic variation were the two exstipulate populations (Curry and San Diego counties), although these populations produced seed (Robison 2006). Though stipulate and exstipulate forms of Cape ivy are nearly equally common in California (Robison et al. 2010), all herbarium collections in its native range, with the exception of one, are of the stipulate type (Balciunas, pers. comm.), Thus, the exstipulate phenotype of Cape ivy appears to be a rare form of the species and may, inherently, have very little genetic variability.

In the first experiment, most growth parameters showed variability among populations of Cape ivy. The plants from San Diego County were larger than plants from the other sites. San Diego is the most southern location and was $760 \mathrm{~km}$ from the next closest population in Marin County (latitude difference of $5.11^{\circ}$ ). By comparison, the Marin, Mendocino and Curry County populations were all within $500 \mathrm{~km}$ of each other (within $4.34^{\circ}$ of latitude). San Diego is also the warmest of the four sites, with average annual maximum and minimum temperatures of 25.9 and $7.5^{\circ} \mathrm{C}$, (Table 1), which is 4 and $2.5^{\circ} \mathrm{C}$ higher, respectively, than the next warmest county. The mean maximum and minimum temperatures during the experiments were 32.4 and $12.8^{\circ} \mathrm{C}$ in the first experiment and 26.0 and $8.7^{\circ} \mathrm{C}$ in the second experiment. Thus, we speculate that in San Diego County genotypes were selected for adaptation to warmer growing conditions, and this was supported by the statistically higher growth in the first experiment. In the cooler conditions of the second experiment, the three northern populations exhibited considerably greater growth compared to the San Diego County population. Adaptive differentiation could be occurring for the colder minimum temperatures in the three northern populations and for the higher maximum temperatures at the southern distribution edge.

Invaders can adapt to selection pressures in their new range with two distinct strategies: either high genetic variation within introduced populations, which can lead to local adaptation, or adaptive plasticity in 
Table 3 Comparison of relative growth rate (RGR), leaf area, leaf number, specific leaf area (SLA), number of internodes, and stem length among four Cape ivy populations at three shading levels in Experiment 1

\begin{tabular}{|c|c|c|c|c|c|c|}
\hline \multirow[t]{2}{*}{ Measurement } & \multirow{2}{*}{$\begin{array}{l}\text { Shading } \\
\text { (\% of full } \\
\text { sunlight) }\end{array}$} & \multirow{2}{*}{$\begin{array}{l}\text { Shading } \\
\text { treatment } \\
\text { significance }\end{array}$} & \multicolumn{4}{|l|}{ Location } \\
\hline & & & Curry & Mendocino & Marin & San Diego \\
\hline \multirow[t]{3}{*}{ RGR } & 100 & $c$ & 0.023 & 0.019 & 0.023 & 0.019 \\
\hline & 20 & $a$ & 0.125 & 0.108 & 0.119 & 0.137 \\
\hline & 6 & $b$ & 0.102 & 0.083 & 0.107 & 0.114 \\
\hline \multicolumn{3}{|l|}{ Location significance } & $a$ & $b$ & $a$ & $a$ \\
\hline \multirow[t]{3}{*}{ Leaf area $\left(\mathrm{cm}^{2}\right)$} & 100 & $c$ & $13(n=1)$ & $10(n=5)$ & $2(n=1)$ & $48(n=3)$ \\
\hline & 20 & $a$ & 1,183 & 711 & 898 & 1,660 \\
\hline & 6 & $b$ & 640 & 329 & 430 & 888 \\
\hline \multicolumn{3}{|l|}{ Location significance } & $a b$ & $c$ & $b c$ & $a$ \\
\hline \multirow[t]{3}{*}{ Leaf number } & 100 & $c$ & $15.7 *$ & $17.1 *$ & $12.7 *$ & $18.0^{*}$ \\
\hline & 20 & $a$ & 148.4 & 101.2 & 109.3 & 226.3 \\
\hline & 6 & $b$ & 55.4 & 38.2 & 46.1 & 70.7 \\
\hline \multicolumn{3}{|l|}{ Location significance } & $b$ & $b$ & $b$ & $a$ \\
\hline \multirow[t]{3}{*}{ SLA } & 100 & $c$ & $94(n=1)$ & $110(n=5)$ & $15(n=1)$ & $160(n=3)$ \\
\hline & 20 & $b$ & 945 & 826 & 767 & 855 \\
\hline & 6 & $a$ & 1,529 & 1,700 & 1,412 & 1,366 \\
\hline \multicolumn{3}{|l|}{ Location significance } & $b$ & $a$ & $a b$ & $a b$ \\
\hline \multirow[t]{3}{*}{ Number of internodes } & 100 & $c$ & $3.0^{*}$ & $3.9 *$ & $3.4^{*}$ & $2.8 *$ \\
\hline & 20 & $a$ & 104.1 & 73.3 & 71.4 & 169.2 \\
\hline & 6 & $b$ & 43.4 & 26.2 & 34.6 & 49.7 \\
\hline \multicolumn{3}{|l|}{ Location significance } & $b$ & $b$ & $b$ & $a$ \\
\hline \multirow[t]{3}{*}{ Total stem length $(\mathrm{cm})$} & 100 & $c$ & $13 *$ & $21 *$ & $15^{*}$ & $16^{*}$ \\
\hline & 20 & $a$ & 4,165 & 2,538 & 2,735 & 6,891 \\
\hline & 6 & $b$ & 1,777 & 855 & 1,554 & 2,701 \\
\hline Location significance & & & $b$ & $b$ & $b$ & $a$ \\
\hline
\end{tabular}

Except where noted (*), these values represent means of measurements taken after 7 weeks of growth. Experimental $n=15$ except where noted. Columns with different letters are significantly different among light treatments at $P \leq 0.05$. Rows with different letters are significantly different among locations at $P \leq 0.05$

* Values reported for week 6; by week 7, leaves in 100\% sunlight in Experiment 1 had become necrotic

genetically depauperate introductions (Mack 1992). We speculate that Cape ivy has relatively low genetic diversity. Other invasive plants have been shown to have low within- and between-population genetic diversity in their introduced range. For example, Williams et al. (1995) and Poulin et al. (2005) found no genetic variation within populations or between any geographical areas in the apomictic perennial bunchgrass crimson fountaingrass (Pennisetum setaceum (Forsk.) Chiov.). This species is a highly successful invader in Hawaii and elsewhere, including Arizona and California. These authors attributed the broad ecological amplitude of the species to phenotypic plasticity and concluded that the original immigrants to the island possessed little genetic variation. Historical records indicate only one known introduction to Hawaii. Although Cape ivy is not apomictic and appears to have more genetic variability than crimson fountaingrass, its response to different light levels was relatively similar among and within populations. This suggests that while there appears to be some level of genetic variation within and between introduced populations, it is limited. Despite the apparent limited variability within Cape ivy populations, our results suggest that multiple introductions have occurred over time. The plant was introduced to California in the 1850s as an ornamental houseplant (Bossard 2000) and it is assumed that multiple introductions to wildland 
Table 4 Comparison of relative growth rate (RGR), leaf area, leaf number, specific leaf area (SLA), number of internodes, and stem length among four Cape ivy populations at three shading levels in Experiment 2

\begin{tabular}{|c|c|c|c|c|c|c|}
\hline \multirow[t]{2}{*}{ Measurement } & \multirow{2}{*}{$\begin{array}{l}\text { Shading } \\
\text { (\% of full } \\
\text { sunlight) }\end{array}$} & \multirow{2}{*}{$\begin{array}{l}\text { Shading } \\
\text { treatment } \\
\text { significance }\end{array}$} & \multicolumn{4}{|c|}{ Location } \\
\hline & & & Curry & Mendocino & Marin & San Diego \\
\hline \multirow[t]{3}{*}{ RGR } & 100 & $c$ & 0.029 & 0.048 & 0.034 & 0.033 \\
\hline & 20 & $a$ & 0.121 & 0.122 & 0.116 & 0.114 \\
\hline & 6 & $b$ & 0.093 & 0.110 & 0.093 & 0.099 \\
\hline \multicolumn{3}{|l|}{ Location significance } & $b$ & $a$ & $b$ & $b$ \\
\hline \multirow[t]{3}{*}{ Leaf area $\left(\mathrm{cm}^{2}\right)$} & 100 & $c$ & 64 & 81 & 72 & 93 \\
\hline & 20 & $a$ & 1,308 & 1,117 & 1,368 & 798 \\
\hline & 6 & $b$ & 315 & 424 & 487 & 448 \\
\hline \multicolumn{3}{|l|}{ Location significance } & \multicolumn{4}{|c|}{ No differences } \\
\hline \multirow[t]{3}{*}{ Leaf number } & 100 & $b$ & 25.8 & 29.0 & 22.7 & 28.1 \\
\hline & 20 & $a$ & 145.9 & 118.1 & 129.8 & 82.2 \\
\hline & 6 & $b$ & 32.1 & 47.4 & 47.6 & 42.0 \\
\hline \multicolumn{3}{|l|}{ Location significance } & \multicolumn{4}{|c|}{ No differences } \\
\hline \multirow[t]{3}{*}{ SLA } & 100 & $b$ & 453 & 527 & 442 & 455 \\
\hline & 20 & $b$ & 604 & 499 & 485 & 544 \\
\hline & 6 & $a$ & 2,012 & 1,024 & 765 & 1,203 \\
\hline \multicolumn{3}{|l|}{ Location significance } & \multicolumn{4}{|c|}{ No differences } \\
\hline \multirow[t]{3}{*}{ Number of internodes } & 100 & $b$ & 8.4 & 11.8 & 12.7 & 9.7 \\
\hline & 20 & $a$ & 96.5 & 79.5 & 85.5 & 56.9 \\
\hline & 6 & $b$ & 18.1 & 27.5 & 30.7 & 23.3 \\
\hline \multicolumn{3}{|l|}{ Location significance } & \multicolumn{4}{|c|}{ No differences } \\
\hline \multirow[t]{3}{*}{ Total stem length $(\mathrm{cm})$} & 100 & $c$ & 32 & 78 & 66 & 51 \\
\hline & 20 & $a$ & 2,713 & 2,610 & 3,124 & 1,695 \\
\hline & 6 & $b$ & 650 & 982 & 1,106 & 965 \\
\hline \multicolumn{3}{|l|}{ Location significance } & \multicolumn{4}{|c|}{ No differences } \\
\hline
\end{tabular}

Values represent means of measurements taken after 7 weeks of growth. Experimental $n=15$. Columns with different letters are significantly different among light treatments at $P \leq 0.05$. Rows with different letters are significantly different among locations at $P \leq 0.05$

areas occurred randomly as house plants were discarded in gardens. In support of this, all of the collection locations used in this study were in areas of current or historic human settlement.

\section{Effect of light}

Cape ivy grew very poorly in full sunlight in both experiments, and in many cases the leaves had become necrotic by the end of the experiment. Although plants growing under $6 \%$ light grew better than those in full sunlight, they were far less robust compared to plants growing at $20 \%$ light. Plants growing under high levels of shade are well recognized to produce less dry matter, develop longer internodes and petioles, and have larger, thinner leaves (Grime 1979). Cape ivy grown under low light produced less shoot and root biomass, had larger, thinner leaves (>SLA compared to higher light treatments), and had internodes that were $15 \%$ longer than leaves grown at 20\% light. Furthermore, plants grown under the lowest light also had fewer numbers of leaves and internodes, and had a lower leaf area and total stem length. In a similar light study (71, 45 and $17 \%$ available sunlight) conducted in South Africa with one population (stipulate form), Rolando (2000) showed that Cape ivy grew best and had the highest flowering rates at $45 \%$ of full sunlight.

Because Cape ivy was introduced through the ornamental industry as a hanging houseplant, it would 
be expected that the species would be well adapted to low light. In these experiments, plants grew best at $20 \%$ of full sunlight, similar to the light levels typical throughout Cape ivy's invaded range. Although two of the four populations (Curry and Mendocino County) were collected in fully exposed areas, they did not differ in their response to the three light levels compared to plants collected under a forested canopy. These populations occupy coastal areas subject to frequent cloudy or foggy days and do not experience light intensities typical of exposed inland sites.

Jubatagrass (Cortaderia jubata (Lem.) Stapf.) is a large tufted perennial grass considered highly invasive in California and southern Oregon and occurs almost exclusively along the coast (Lambrinos 2001; Stanton and DiTomaso 2004). Like Cape ivy, jubatagrass reaches maximal growth in moderate light intensities (60\% of full sunlight) typical of coastal regions with frequent fog and cloud cover (Stanton and DiTomaso 2004). Unlike Cape ivy, jubatagrass does not typically occur under forest canopies or in riparian areas. Its habitat is generally in open disturbed coastal sites. Thus, it would be expected to show optimal growth at light levels below full sunlight, but not at the low light levels expected of Cape ivy.

Cape ivy has been compared to kudzu (Pueraria montana (Lour.) Merr.) in its growth form, habit, and ecosystem impacts (Moore 1997). While both invasive species are perennial vines that climb over other vegetation, kudzu overtops its competition and grows in areas of high light intensity in the southern and eastern United States. In an experiment comparing the growth response of kudzu to three light levels (full sunlight, 55 and $25 \%$ of full sunlight), Fujita et al. (1993) found it to thrive under both full sunlight and shading. At $55 \%$ of full sunlight, above-ground biomass increased by $55 \%$ compared to the full sunlight treatments, but below-ground biomass decreased by $32 \%$. Even at $25 \%$ of full sunlight, there was only a $12 \%$ reduction in above-ground biomass, but a more dramatic $64 \%$ reduction in below-ground biomass compared to the full sunlight treatment.

Based on the differential response to light between Cape ivy and kudzu, it is very unlikely that Cape ivy will become as significant a problem as kudzu in forested or riparian areas of the United States. Our data show that Cape ivy will not persist in areas with prolonged high intensity sunlight, characterized by much of the interior regions of California and Oregon.
Alternatively, it is expected to invade and persist in areas with reduced light, including coastal regions frequently exposed to fog or cloudy conditions, or subcanopy layers of riparian areas or woodlands. This is supported by our previous work (Robison et al. 2010), where field collections showed that Cape ivy was well established in five different broad community types (urban/agriculture, Eucalyptus forests, coastal scrub, riparian forest, and oak woodland). All these communities are consistent with areas that have reduced light intensity. Using CLIMEX modeling, Cape ivy infestations were predicted to be primarily restricted to coastal California, particularly in areas with coastal fog influence and in coastal riparian areas with adequate moisture (Robison 2006). This is in agreement with its community associations in its native range of South Africa (Rolando 2000), where Cape ivy grows primarily in moist, shady environments along forest edges.

Early detection and eradication of new invasive plant populations is the most cost-effective prevention strategy for new introductions, and is also critical for containing existing invasive plant populations and developing effective management programs. However, determining which invasive plant species are most important to monitor for early detection in any given area can be deceptively difficult. Given the sheer number of potential invaders, it is essential that land managers are able to determine the most probable invaders for their region and to delineate the most susceptible sensitive habitats within their region. The genetic variability of Cape ivy appears to be relatively limited and populations will be restricted to areas not exposed to high intensity light, such as coastal environments and sub-canopy layers of riparian or woodland communities. Thus, early detection and rapid response efforts need to target these communities to prevent future introduction or expansion of Cape ivy along the coast of California and Oregon.

Open Access This article is distributed under the terms of the Creative Commons Attribution Noncommercial License which permits any noncommercial use, distribution, and reproduction in any medium, provided the original author(s) and source are credited.

\section{References}

Alvarez ME, Cushman JH (2002) Community-level consequences of a plant invasion: effects on three habitats in coastal California. Ecol Appl 12:1434-1444 
Bossard CC (2000) Delairea odorata. In: Bossard CC, Randall JM, Hoshovsky MC (eds) Invasive plants of California's Wildlands. University of California Press, Berkeley, pp 154-158

Conover WJ, Iman RL (1981) Rank transformations as a bridge between parametric and nonparametric statistics. Am Stat 35:124-129

Fujita K, Matsumoto K, Ofosu-Budu GK, Ogata S (1993) Effect of shading on growth and dinitrogen fixation of kudzu and tropical pasture legumes. Soil Sci Plant Nutr 39:43-54

Grime JP (1979) Plant strategies and vegetation processes. Wiley, Chichester

Grobbelaar E, Neser OC, Neser S (1999) A survey of the potential insect biological control agents of Delairea odorata Lemaire in South Africa. Plant Protection Research Institute, Agricultural Research Council, Pretoria, South Africa, p 63

Hilliard OM (1977) Compositae in Natal. University of Natal Press, Pietermaritzburg, South Africa

Hunt R (1978) Plant growth analysis. Camelot Press Ltd, Southhampton

Institute SAS (2005) JMP, Version 6.0. SAS Institute Inc, Cary

Lambrinos JG (2001) The expansion history of a sexual and asexual species of Cortaderia in California, USA. J Ecol 89:88-98

Mack RN (1992) Characteristics of invading plant species. In: Stone CP, Smith CW, Tunison JP (eds) Alien plant invasions in native ecosystems of Hawaii: management and research. University of Hawaii, Honolulu, pp 42-46
Moore K (1997) Battling the kudzu of the west. Controlling cape ivy (formerly German ivy) by hand removal. CalEPPC News 5:4-5

Poorter H, Garnier E (1999) Ecological significance of inherent variation in relative growth rate and its components. In: Pugnaire FI, Valladares F (eds) Handbook of functional plant ecology. Marcel Dekker, New York, pp 81-120

Poulin J, Weller SG, Sakai AK (2005) Genetic diversity does not affect the invasiveness of fountain grass (Pennisetum setaceum) in Arizona, California and Hawaii. Divers Distrib 11:241-247

Robison RA (2006) Distribution, growth analysis and reproductive biology of Cape ivy (Delairea odorata Lem. syn Senecio mikanioides Walp.) in California. Dissertation, Division of Plant Biology. University of California, Davis

Robison R, Plant R, DiTomaso JM (2010) Distribution and community associations of Cape ivy (Delairea odorata Lem.) in California. Madroño (In Press)

Rolando C (2000) The reproductive biology, natural predators and biological control of Delairea odorata Lem. Botany and Zoology. University of Natal, Pietermaritzburg, p 162

Stanton AE, DiTomaso JM (2004) Growth response of Cortaderia selloana and Cortaderia jubata (Poaceae) seedlings to temperature, light, and water. Madroño 51:312-321

Williams DG, Mack RN, Black RA (1995) Ecophysiology of introduced Pennisetum setaceum on Hawaii: the role of phenotypic plasticity. Ecology 76:1569-1580 